\title{
Three Models of English Morphology
}

\author{
Barli Bram \\ Sanata Dharma University \\ barli@usd.ac.id
}

\section{Abstract}

This paper explores models of English morphology, namely Item and Arrangement (IA), Item and Process (IP), and Word and Paradigm (WP), which can be used to analyze morphological data, particularly word formation involving prefixes and suffixes. Sample data, consisting of complex words or words having more than one morpheme, were analyzed using the three models to discover their strengths and shortcomings. In order to find out the differences between the three models of morphology, it is important that the current writer should examine strategies for distinguishing between derivational affixes and inflectional ones. There exist three advantages if morphologists know very well the three models of English morphology. First is that IA fails to display a clear sequence of the item and arrangement when dealing with some irregular plural nouns and irregular past tense. Second is that IP offers a better solution to irregular plural nouns, such as mice and men. Third is that WP appears to be the most efficient model when dealing with inflectional morphology.

Keywords: Item and Arrangement (IA), Item and Process (IP), Word and Paradigm (WP), derivation, inflection

\section{A. INTRODUCTION}

In this paper, the current author compares and contrasts the three models of morphology, namely Item and Arrangement (IA), Item and Process (IP), and Word and Paradigm (WP), in order to account for analyses of complex words in English. will first look at three aspects which seem to be able to clearly and neatly differentiate between inflection and derivation. As we will see below, the main difference between inflection and derivation lies in their function. The former yields forms of lexemes and the latter new lexemes (Bauer, 2003: 91; Booij, 2005: 112; Booij, 2006: 654). It is essential to keep in mind that the borderlines between the two kinds of morphology will become complicated when we try to analyse more data. Accordingly, we would want to remind ourselves that it is in fact not always easy to decide whether we are dealing with an inflectional or derivational affix in a given context.

\section{B. INFLECTION AND DERIVATION}

To begin our discussion, let us now agree that in principle English Morphology can be divided into two categories namely inflection and derivation, we might find it necessary to examine what lies behind this dichotomy approach. Bauer (2003: 14-15) lists the following three major strategies of differentiating between an inflectional affix and derivational one: 
1. Listing the categories (of the base, stem and new word-form)

2. Identifying the affix meaning

3. Checking the productivity

Below we will observe how the

three ways work. By the phrase

"listing the categories (of the base, stem and new word-form)", we mean that we see what part of speech we have after an affix in English, normally either a prefix or suffix, is combined with a base or stem. If a new wordform and its base belong to different categories, we may then conclude that it is derivation, and if the new wordform and its stem are of the same category and the affix involved is a suffix, we would say that this is inflection (Bauer, 2003: 14).

Table 1 summarizes the above points.

\begin{tabular}{|l|l|l|l|}
\hline No. & Base/Stem & Complex Word & $\begin{array}{l}\text { Inflection/Deriv } \\
\text { ation }\end{array}$ \\
\hline 1. & start (V, stem) & start.ed $(\mathrm{V})$ & Inflection \\
\hline 2. & $\begin{array}{l}\text { computer }(\mathrm{N}, \\
\text { stem) }\end{array}$ & computer.s $(\mathrm{N})$ & Inflection \\
\hline 3. & large (Adj, base) & en.large $(\mathrm{V})$ & Derivation \\
\hline 4. & hospital (N, base) & hospital.ize (V) & Derivation \\
\hline 5. & do $(\mathrm{V}$, base) & redo $(\mathrm{V})$ & Derivation \\
\hline 6. & correct (Adj, base) & incorrect (Adj) & Derivation \\
\hline
\end{tabular}

The second strategy is to identify the meaning of the affix of a complex word. In English, inflection always carries a regular meaning and derivation may or may not do so (Bauer, 2003: 14-15). Take, for instance, the inflectional affixes -ed and $-s$ in the table above. The meaning of the suffix -ed which is added to a regular present tense verb as in started is constant, namely either 'past tense' or 'past participle', depending on context. Similarly, the meaning of the inflectional suffix $-s$ which is combined with a singular countable noun as in computers is the same at all times, that is, 'plural'.

Now let's raise this question: What is the meaning of the derivational prefix en- as in the words enlarge, endanger and encourage? Firstly, we can say that the prefix enmeans 'to make $\mathrm{X}$ ', where $\mathrm{X}$ may refer to any adjective. Therefore, enlarge means 'make (an object) large' as in Tita will enlarge the lovely picture soon. Secondly, we might want to say that the derivational affix en- also means 'to make somebody or something have $\mathrm{X}^{\prime}$ as in the verb encourage. So, encourage may mean 'to make somebody or something have courage' as in the sentence Professors encourage their students to express their ideas. Thirdly, en- might also mean 'to put (somebody or something) in $\mathrm{X}^{\prime}$, where $\mathrm{X}$ refers to any noun. Thus, the complex word endanger means 'to put somebody or something in danger' as in the sentence One should not endanger one's life. To conclude, we see here that the meaning of the derivational prefix en- tends to be irregular.

Table 2 summarizes the second strategy, which helps us to point out the distinction between inflection and derivation. 


\begin{tabular}{|l|l|l|l|}
\hline No. & $\begin{array}{l}\text { Affix } \\
\text { (Prefix/Suffix) }\end{array}$ & Meaning (Regular/Irregular) & $\begin{array}{l}\text { Inflection/Deriv } \\
\text { ation }\end{array}$ \\
\hline 1. & -ed eg start.ed & $\begin{array}{l}\text { 'past tense' or 'past participle' } \\
\text { (regular) }\end{array}$ & Inflection \\
\hline 2. & -s eg computer.s & $\begin{array}{l}\text { 'plural' or 'more than one' } \\
\text { (regular) }\end{array}$ & Inflection \\
\hline 3. & $\begin{array}{c}\text { en- eg a. } \text { en.large, } \\
\text { b. } \text { en.courage } \\
\text { and c. } \\
\text { en.danger }\end{array}$ & $\begin{array}{l}\text { At least three possible, irregular } \\
\text { meanings: } \\
\text { a. 'to make X' } \\
\text { b. 'to make sb/sth have } \mathrm{X}^{\prime} \\
\text { c. 'to put in X' }\end{array}$ & Derivation \\
\hline
\end{tabular}

The third strategy is to check the productivity of the affix. In this context, productivity refers to the extent of an affix which can be used to create new word-forms (Bauer, 2003: 70). For clarification, let us once again refer to Table 2 . We classify -ed into inflectional affixes because it can basically be combined every (regular) present tense verb. The suffix -s meaning 'plural' is also categorized into inflection, and it is extremely productive because it can be added to the majority of singular countable nouns. On the other hand, the derivational affix en- can be combined only with certain, limited adjectives and nouns. In today's English, we do not, for example, add en- to glad, hot or campus to come up with the verbs englad 'to make sb/sth glad', enhot 'to make sth hot' or encampus 'to put sb/sth into campus'. These are, nevertheless, possible English words. This seems to further lead us to say that derivation is less productive than inflection.

As we have seen above, there are three main properties which may help us to distinguish inflection from derivation in English namely the category, meaning and productivity. Up to this point, it appears to be easy for us to split morphology into inflection and derivation. If we examine more data, however, we find out that that is not always the case.
For example, let us take the first factor, namely category or part of speech, which has earlier been said to able to show differences between inflection and derivation. The statement that 'if an affix changes the category of the base, it is then derivation' is not always valid. For example, we can combine the suffix -ly with the adjective quick to form the adverb quickly. In this context, the suffix -ly turns the category of the base, an adjective, into an adverb. Is ly an inflectional affix, then? Based on our 'guideline' (that is categorychanging), we would want to say 'yes'. But at the same time, following Haspelmath (2002: 60), we might want to ask these three questions (and perhaps doubt our previous positive answer): Do quickly and quick belong to different lexemes? Or is quickly a new word-form of the lexeme quick? To put it in another way, does the suffix -ly above function as inflection or derivation?

To sum up, in relatively a larger number of cases, it seems, we can set apart inflection from derivation when dealing with English morphology. In some, if not many, other cases, however, we may often become doubtful to decide between inflection and derivation. The dichotomy approach does not apply successfully all the time. 
C. ITEM AND ARRANGEMENT (IA) AND ITEM AND PROCESS (IP)

"The 'Item and Process' model is better, for a language like English, than the 'Item and Arrangement' model" (Matthews, 1998: 145). What are the arguments for Matthews's conclusion above and are there any counter-arguments? In the following, the present writer will first clarify the Item and Arrangement (IA) as well as the Item and Process (IP) models. Then the current author will present the arguments for preferring IA in tackling English morphology. Next, the author will also put forward some counter-arguments.

\section{Item and Arrangement Model (Morpheme-based Morphology)}

The Item and Arrangement (IA) model refers to a grammar which presents the list of the morphs and a set of rules for arranging the morphs (Bauer, 2004: 60). In other words, IA views a language consisting of a list of components which follow certain patterns or arrangements (Aronoff and Fudeman, 2005: 47). Take, for example, these three plural nouns: buds, necks and glasses. Here we find three morphs or items namely /z/, /s/ and / Iz/ which signify the meaning of plurality, and we can also say the three are variant forms of the morpheme $\{-s\}$ (regular plural suffix). To account for the three plural nouns above using IA, we can arrange the morphs in sequences as follows:

\begin{tabular}{|c|c|c|}
\hline 1 & {$[\mathrm{~b} \boldsymbol{\Lambda} \mathrm{d}]$} & $+\quad[$ \\
\hline 2 & {$[$ nek $]+$} & + \\
\hline 3 & [gla:s] + & + \\
\hline
\end{tabular}

As we have seen above, the morphs $\{$ bud\}, \{neck\} and \{glass\}, respectively pronounced as $[\mathrm{b} \Lambda \mathrm{d}]$, [nek] and gla:s] are combined with a certain variant of the morpheme $\{-s\}$. Notice that the morpheme is phonologically conditioned. If the final consonant sound of a stem is voiced as in [b $\boldsymbol{\Lambda} \mathrm{d}]$, we add $/ \mathrm{z} /$ to the stem. If $\mathrm{a}$ stem ends in a voiceless consonant sound as in [nek], we combine the stem with /s/. Next, if the final sound of a stem is a sibilant or strident such as [gla:s], we then add /Iz/ or /əz/ to the stem.

To put it another way, in IA we divide words into separate morphs. For instance, in the word form necks we may also say that the plural noun is made up of two morphs /nek.s/ namely /nek/ and /s/. In this context, a morph refers to "the realization of a morpheme" which is an abstract component to represent "form and meaning" correspondence (Bauer, 2003: 334-45).

\section{Item and Process Model (Lexeme-based Morphology)}

The Item and Process (IP) model may be defined as a grammar which spells out elements or items as a fundamental form which then yields allomorphs through phonological operations (Bauer, 2004: 60). For elaboration, let us refer to the plural marker $\{-s\}$ in these nouns: buds, cars, necks and glasses. Supposed we all agree that the underlying form of $\{-\mathrm{s}\}$ is /z/. In the three words above, we find phonological processes where $\{-$ s\} may become or be realized into /z/, /s/ or / Iz/. If the final consonant sound of a stem is voiced as in [b $\boldsymbol{\Lambda} \mathrm{d}]$ and [ka:], the $\{-\mathrm{s}\}$ will become $/ \mathrm{z} /$.

Further, we can say that /s/ and /Iz/ or /oz/ are derived from the underlying form $/ z /$. As we observe, the $\{-s\}$ becomes $/ \mathrm{s} /$ in the noun necks, whose stem ends in a voiceless consonant sound namely $/ \mathrm{k} /$. Whereas $\{-\mathrm{s}\}$ in the plural noun glasses, whose stem ends in a strident or sibilant namely /s/, the $\{$-s $\}$ will become /Iz/ or /oz/ (weak form). We see above that the lexemes BUD, SEA, 
NECK and GLASS undergo the process of pluralization and the morpheme may become /z/, /s/ or /Iz/ or /əz/, depending on the final sound of the stem.

Matthews (1998) says the Item and Process model can be used to analyze inflections, both regular and exceptional ones, in a consistent way. Below is an example taken from Matthews (1998: 127) to account for the regular plural noun seas; Here, we say seas is derived from the lexeme SEA which undergoes the process of pluralization and the morpheme is realized into /z/.

Next, to apply IP to account for irregular, exceptional plural forms such as feet, teeth and geese, we say that the three are derived from FOOT, тоотH and GOOSE which have undergone the operation of pluralizing by changing the vowel sound /u/ or /u:/ to the long one /i:/ (Matthews, 1998: 129).

To account for Past Tense and Past Participle such as spammed and (have) spammed, we can apply a similar formula: "X $\rightarrow \mathrm{X}+[\mathrm{d}]$ ", where $\mathrm{X}$ represents a verb (Matthews, 1998: 128). In this context, both forms of spammed result from the lexeme SPAM which goes through the processes of 'becoming past tense' and 'becoming past participle' respectively.

As we can observe above, the IP formulae have so far worked consistently in dealing with regular and irregular pluralization, the past tense and past participle.

\section{a. IP Pro-arguments}

Now suppose we would like to analyze the italicized words in the following sentence:

Last Saturday I saw thousands of sheep which will be sold. Which morphological model can or should we use: IA or IP? If we use IA, it turns out we will face difficulty in splitting up saw (past tense of see), sheep (plural) and sold (past participle) into separate morphs in order to make the items and their arrangements apparent so that we can see a direct connection between form and meaning. Unlike in kiwis and attended, where we see the sequences of $\{$ kiwi $\}+\{-s\}$ and $\{$ attend $\}+\{$-ed $\}$ and the correlation between the four elements, there is no similar sort of arrangement in saw, sheep and sold. As a result, IA turns out to be ineffective in dealing with irregular forms such as saw, sheep and sold. In IA or morpheme-based morphology, "a one-one correspondence between form and function" is crucial (Spencer, 1991: 57). The problem with the two sample words is that they have no visible, concrete item or morph to show plurality in sheep and 'past tense' in saw.

If we use IP to tackle the data analyses above, we would say that the word form saw is derived from the lexeme SEE which undergoes the process of 'becoming past tense' and that the word form sheep (plural) results from the lexeme SHEEP which goes through the operation of pluralization. Similarly, we say that sold results from SELL which undergoes the process of 'becoming past participle'. As the above clarification shows, IP proves to be a better tool than IA in dealing with English morphology, particular inflectional morphology.

\section{b. IP Counter-arguments}

As a matter of fact, IA can still be used to account for the plural sheep. The analysis will be: sheep + zero morph. As for saw and sold, the items and arrangements are respectively as follows: see $+e d$ and sell + ed. Nevertheless, this does not seem to be consistent with the basic idea of morpheme-based morphology, where a one-one correspondence 
between a morpheme and meaning is expected.

\section{WORD AND PARADIGM (WP)}

Now, our next question is: Is the third model called Word and Paradigm (WP) than the first two discussed earlier? In other words, does consideration of Word and Paradigm change our conclusion about how to deal with English morphological analysis?

The third model of morphology, which is called Word and Paradigm (WP), focuses on wordforms associated with their respective lexemes and the word-forms function as the basic elements (Bauer, 2004: 111). Bauer (2003: 197-8) also says that WP can be synonymous with amorphous morphology. Haspelmath (2001: 47) uses the term 'the wordbased model' to refer to WP and points out that the word is the main component, and the word is not split up into items but is formulated using word-schemas.

Based on Haspelmath's (2001: 47) model, the plural nouns doors, bottles, computers, mugs, curtains, roads and crabs, for instance, can be presented in the word-schema below: (a). keys, bottles, computers, mugs, curtains, roads, crabs

\section{(b). /Xz/ \\ $\mathrm{N}$}

\section{'plurality of xs'}

The word-schema above may represent the entire set of regular plural nouns. We notice that the variable /X/ may represent a different final sound of a word-form such as /i:/ in key, /l/ in bottle, /ə/ in computer, /g/ in mug, /n/ curtain, /d/ in road and /b/ in crab. All of these word-forms (singular nouns) end in a voiced sound and accordingly the plural marker $-s$ will realize into /z/. In other contexts, it may realize into /s/ after a voiceless sound or /Iz/ after a strident or sibilant. WP appears to be concise.

Regarding the word-based theory, Scalise (1986: 62) says that it "has as many supporters as opponents..." Hockett (1954), Robins (1959) Matthews (1998), and Bauer (2004) say that WP was originally used to tackle ancient Greek and Latin, which were highly inflected. Suppose that we all agree that English of today is, however, no longer highly inflectional. But we might still want to say Word-and-Paradigm is relevant for us to apply when dealing with English morphology, particularly inflectional one. One of the main reasons is that WP captures wordforms more efficiently than IA and IP do, by using word-schemas.

Nevertheless, questions about how to deal with derivational morphology using WP still require satisfactory answers. For example, how should we account for wordforms such as wordy and blacken?

\section{E. CONCLUSION}

Why is the knowledge of the three models of morphology important? There are three advantages to gain if we manage to capture a picture of the three models of English morphology. Firstly, we see that IA fails to display a clear sequence of the item and arrangement when dealing with a number of irregular plural nouns (eg mice and men) and irregular past tense (eg spoke and sang, to mention a few examples. As pointed out earlier, the main obstacle here is that we encounter difficulty in dividing the words into separate morphemes. As a result, we might want to use (an)other model(s) when trying to solve morphological problems such as the above. Secondly, we notice that IP, as Matthews (1998) also concludes, gives a better solution to the 
problematic, irregular words such as mice and men. For instance, the plural mice may be said to have derived from MOUSE which undergoes the process of pluralization and the [au] becomes [ai]. Thirdly, we have thus far found WP the most efficient model when dealing with inflectional morphology.

\section{REFERENCES}

Aranoff, Mark and Kirsten Fudeman (2005). What Is Morphology? Malden, MA: Blackwell.

Bauer, Laurie (2003 [1988]). Introducing Linguistic Morphology. 2nd ed. Edinburgh: Edinburgh University Press. Bauer, Laurie (2004). A Glossary of Morphology. Edinburgh: Edinburgh University Press.

Booij, Geert (2005). The Grammar of Words. Oxford: Oxford University Press.

Booij, Geert (2006). "Inflection and Derivation" in Keith Brown (ed) Encyclopedia of Language and Linguistics. 2nd ed. Amsterdam:

Elsevier. V, 654-61.

Haspelmath, Martin (2001).

Understanding Morphology. Harlow, Essex: Pearson Education.

Haspelmath, Martin (2002).

Understanding Morphology. Harlow,

Essex: Pearson Education

Hockett, F. Charles (2004 [1954]).

"Two Models of Grammatical Description" in Francis Katamba (ed) Morphology. London and New York: Routledge. I, 110-36.

Matthews, P.H. (1998). Morphology. Cambridge: Cambridge University Press.

Robins, R.H. (2004 [1959]). "In Defence of WP" in Francis Katamba (ed) Morphology. London and New York: Routledge. I, 137-56.
Scalise, Sergio (1986). Generative

Morphology. 2nd ed. Dordrecht: Foris Publications.

Spencer, Andrew (1991).

Morphological Theory. Oxford: Basil Blackwell. 